\title{
Effect of ultraprotective mechanical ventilation on right ventricular function during extracorporeal membrane oxygenation in adults with acute respiratory distress syndrome
}

\author{
Tommaso Pettenuzzo ${ }^{1}$, Maxime Pichette ${ }^{1}$, Ghislaine Douflé ${ }^{1}$, and Eddy Fan ${ }^{1}$ \\ ${ }^{1}$ University of Toronto
}

August 23, 2020

\begin{abstract}
Background: Right ventricular dysfunction (RVD) is frequent in patients suffering from acute respiratory distress syndrome (ARDS). Veno-venous extracorporeal membrane oxygenation (V-V ECMO) may allow the use of ultraprotective mechanical ventilation (MV) in the most severe cases of ARDS. However, the effects of this MV strategy on RV function are not well known. We investigated with echocardiography the prevalence and evolution of RVD in patients supported with V-V ECMO for severe ARDS and ventilated with an ultraprotective ventilation approach. Methods: Eighteen patients who required V-V ECMO for severe ARDS and were assessed with echocardiography before and after cannulation between January 2014 and December 2017 were enrolled in this retrospective observational study. Results: Before cannulation, RV dilatation was present in $6 / 16$ (37\%) and 10/17 (59\%) patients, according to quantitative and qualitative assessment, respectively, and RVD was reported in 9/14 (64\%) patients. After cannulation, tidal volume, plateau pressure, and driving pressure significantly decreased [median (interquartile range) values were $2.0(0.9-3.6) \mathrm{mL} / \mathrm{kg}, 20(20-20) \mathrm{cmH} 2 \mathrm{O}$, and $10(10-10) \mathrm{cmH} 2 \mathrm{O}$, respectively] and RV size and function were similar as before cannulation. Except for $\mathrm{SaO} 2$ before cannulation, which was significantly lower in non-survivors, no other risk factor for RVD, RV dilatation, or mortality was identified in our population. Conclusions: In patients requiring V-V ECMO for severe ARDS, RVD and dilatation before ECMO cannulation were frequent but not associated with worse clinical outcomes. An ultraprotective MV strategy was not accompanied by a worsening of RV function.
\end{abstract}

\section{Manuscript \\ INTRODUCTION}

Right ventricular dysfunction (RVD) commonly complicates the management of patients with acute respiratory distress syndrome (ARDS). ${ }^{1}$ The most severe form of RVD, acute cor pulmonale (ACP), occurs in up to one-quarter of ARDS patients. ${ }^{2}$ The pathophysiology of RVD in ARDS is multifactorial, depending on the injury to pulmonary circulation and subsequent pulmonary vascular dysfunction, potential injurious ventilatory settings, and metabolic derangements (such as hypoxemia, hypercapnia, and acidemia). ${ }^{2}$ Of note, the use of mechanical ventilation per se can promote RVD by inducing extra-alveolar or intra-alveolar vascular collapse as a consequence of alveolar atelectasis or overdistension at the extremes of lung volumes or airway pressures and by decreasing RV preload through the increase in pleural pressure. ${ }^{2}$ By potentially causing low cardiac output and systemic venous congestion, ${ }^{2}$ RVD may contribute to the development of multiorgan failure in patients with ARDS. ${ }^{3}$ Although several authors found RV failure in ARDS to be associated with mortality ${ }^{4-6}$ other groups did not find such an association. ${ }^{7,8}$

Venovenous ECMO (V-V ECMO) is a therapy in patients with ARDS unresponsive to conventional management. ${ }^{9}$ Preclinical studies ${ }^{10,11}$ and small case series ${ }^{12-14}$ suggested that, although not directly affecting cardiac function, V-V ECMO may improve RV function through improvements in gas exchange and 
an ability to reduce the need for deleterious ventilatory settings. The best mechanical ventilation (MV) strategy during V-V ECMO has not yet been defined. ${ }^{15} \mathrm{At}$ our center, an ultraprotective ventilation approach is applied during extracorporeal support to minimize the risk for ventilator-induced lung injury (VILI). However, in the context of the extremely low respiratory system compliance $(\mathrm{Crs})$ that is typical of patients with severe ARDS supported with V-V ECMO, alveolar collapse, increased pulmonary vascular resistance and RVD may occur with these settings, ${ }^{1}$ thereby potentially contributing to worse outcomes. ${ }^{5,6}$

We conducted a retrospective observational study to assess the prevalence and evolution of RVD with echocardiography in patients supported with V-V ECMO for severe ARDS and ventilated with an ultraprotective ventilation strategy.

\section{MATERIALS AND METHODS}

\section{Patients}

We included consecutive patients admitted to the medical-surgical intensive care unit (ICU) who were supported with V-V ECMO for severe ARDS and had at least one transthoracic (TTE) or transesophageal (TEE) echocardiography performed within one month before cannulation and during the first week after cannulation. The study period was between January 2014 and December 2017. This study was approved by the Research Ethics Board of the University Health Network and performed in accordance with the ethical standards as laid down in the 1964 Declaration of Helsinki and its later amendments or comparable ethical standards.

Baseline patients' characteristics, ventilatory and hemodynamic variables before and after cannulation, as well as outcome data were collected for all patients from the electronic patient health records. All patients were mechanically ventilated with an ultraprotective MV strategy after ECMO implantation: pressure control of $10 \mathrm{cmH}_{2} \mathrm{O}$, positive end-expiratory pressure (PEEP) of $10 \mathrm{cmH}_{2} \mathrm{O}$, a fraction of inspired oxygen $\left(\mathrm{FiO}_{2}\right)$ of $30-50 \%$ and a respiratory rate of 10 breaths per minute. The static Crs was calculated as the ratio between tidal volume and driving pressure $(\Delta \mathrm{P})$, i.e., the difference between plateau pressure (Pplat) and total PEEP.

The TTE and TEE were ordered by the clinical team for clinical indications. Only the exams with an official report retrievable from the electronic patient health record system were included. Operators who were trained in advanced critical care echocardiography performed all the echocardiographic studies. Images were digitally stored and analyzed by cardiologists in accordance with current American Society of Echocardiography guidelines. ${ }^{16}$ RVD was defined as tricuspid annular plane systolic excursion (TAPSE) $<17 \mathrm{~mm}$, pulsed Doppler S' (RV S') wave $<9.5 \mathrm{~cm} / \mathrm{s}$, or RV fractional area change (RVFAC) $<35 \%$. RV dilatation was defined as basal diameter $>4.1 \mathrm{~cm}$. Left ventricular (LV) systolic dysfunction was defined as left ventricular ejection fraction $(\mathrm{LVEF})<54 \%$ for women and $<52 \%$ for men.

\section{Statistical analysis}

Continuous variables were expressed as median and interquartile range (IQR) and were compared using the Wilcoxon matched-pairs signed-rank test. Categorical variables were expressed as number and percentage and were evaluated using the McNemar test. Our primary objective was to assess the variation of the ventilatory, hemodynamic, and echocardiographic variables with V-V ECMO cannulation. In an exploratory analysis, we investigated the association between RVD and RV dilatation with patient characteristics, ventilatory and hemodynamic variables before ECMO cannulation, and clinical outcomes (duration of invasive MV, duration of V-V ECMO, 28-day vasopressor-free days, ICU and hospital length of stay and mortality). Twenty-eight-day vasopressor-free days were calculated as the number of days that patients were both alive and free of vasopressor support during the first 28 days of ICU admission. Finally, the association between measurements of RV function and ECMO blood flow and sweep gas flow and gas exchange variables was tested with Pearson correlation coefficient. Two-tailed p-values $<0.05$ were considered significant. All the analysis was performed using STATA 14.1 (StataCorp, College Station, TX).

\section{RESULTS}


We included eighteen patients (Table I). Due to the high number of missing echocardiographic exams and measurements in the echocardiographic reports, many patients were excluded during the study period (Supplemental Digital Content I). Seven (39\%) patients were referred from an external hospital. The median (IQR) duration of V-V ECMO support was 8 (6-12) days. Three (17\%) patients required re-cannulation for respiratory failure after the first decannulation. A configuration conversion was necessary in two (11\%) patients, one from bicaval dual lumen-ECMO to femoro-jugular V-V ECMO, and the other from V-V ECMO to veno-venous-arterial-ECMO (the latter was performed after the final echocardiography). One patient was diagnosed with an internal jugular vein thrombus and pulmonary embolism 4 days after decannulation. Four (22\%) patients died in the ICU, all of them during V-V ECMO support. Nine (50\%) patients were discharged home, $3(17 \%)$ to another acute care facility, and $2(11 \%)$ to a rehabilitation center.

Hemodynamic, ventilatory and echocardiographic variables are reported in Table II. Missing data in the echocardiographic report were frequent. Before cannulation, median (IQR) tidal volume was 380 (300-410) $\mathrm{mL}$, corresponding to $5.2(5.0-6.2) \mathrm{mL} / \mathrm{kg}$ of predicted body weight (PBW). The median (IQR) values of Pplat, $\Delta \mathrm{P}$, and Crs were $30(30-34) \mathrm{cmH}_{2} \mathrm{O}, 18(18-20) \mathrm{cmH}_{2} \mathrm{O}$, and 21 (19-23) $\mathrm{mL} / \mathrm{cmH}_{2} \mathrm{O}$, respectively. The ratio between the arterial partial pressure of oxygen $\left(\mathrm{PaO}_{2}\right)$ and the $\mathrm{FiO}_{2}$ before cannulation was 80 $(62-87) \mathrm{mmHg}$. Immediately after cannulation, median tidal volume decreased to $150(58-267) \mathrm{mL}$ (p < $0.01)$, corresponding to $2.0(0.9-3.6) \mathrm{mL} / \mathrm{kg} \mathrm{PBW}(\mathrm{p}<0.01)$. Pplat and $\Delta \mathrm{P}$ decreased, while Crs did not significantly diminish, and $\mathrm{PaO}_{2}$ improved to $92(72-135) \mathrm{mmHg}(\mathrm{p}=0.02)$. After cannulation, heart rate and mean arterial pressure were not significantly different, whereas vasopressor support significantly increased. Median (IQR) ECMO blood flow was 4.45 (3.85-4.95) L/min, sweep gas flow 4.0 (3.0-4.0) L/min, and fraction of sweep gas oxygen $\left(\mathrm{FsO}_{2}\right)$ of $100(100-100) \%$.

The pre- and post-ECMO echocardiographic exams were performed a median (IQR) of 1 (0-6) days before ECMO cannulation and 4 (1-6) days after cannulation, respectively. The majority of these exams (83\%) were TTEs. No hemodynamic or respiratory changes were implemented during the echocardiograms. Before cannulation, RV size was dilated in 6/16 (37\%) patients according to RV basal diameter and in 10/17 (59\%) patients according to the qualitative assessment of RV size (severe dilatation in 3 patients, moderate in 2 patients, and mild in 5 patients). The median (IQR) values of TAPSE, RV S', and RVFAC were 15 (1320) $\mathrm{mm}, 11.0(9.0-12.0) \mathrm{cm} / \mathrm{s}$ and $29(22-34) \%$, respectively. According to the measurement of TAPSE, RV S', and RVFAC, RVD was observed in $57 \%, 36 \%$, and $67 \%$ of patients, respectively. According to any measurement of RV systolic function, RVD was reported in 9/14 (64\%) patients. The median (IQR) value of estimated right ventricular systolic pressure (RVSP) before cannulation was 58 (43-79) mmHg. Tricuspid regurgitation (TR) was assessed in 16/18 patients: 7 patients were measured with no TR or trace TR, 4 patients with mild TR, 3 patients with mild-moderate TR, 1 patient with moderate-severe TR, and 1 patient with severe TR. The median LVEF was 60 (60-63)\%, and no patient had LV dysfunction.

After cannulation, RV dilatation was found in 5/9 (55\%) patients according to RV basal diameter and in $6 / 12(50 \%)$ patients according to the qualitative assessment of RV size (severe dilatation in 2 patients, moderate in 1 patient, and mild in 3 patients). The RV systolic function was not significantly different after ECMO initiation. The median (IQR) values of TAPSE, RV S', RVFAC were 15 (13-18) mm, 12.0 (9.5-13.5) $\mathrm{cm} / \mathrm{s}$, and 23 (20-29) \%. According to any measurement of RV systolic function, RVD was reported in 6/12 $(50 \%)$ patients $(\mathrm{p}=0.08)$. After cannulation, RVSP significantly decreased. Within-patient differences of RV size and function variables after cannulation are reported in Table III. RV basal diameter increased by mean (percentage) $0.1 \mathrm{~cm}(3 \%)$, TAPSE increased by mean (percentage) $1 \mathrm{~mm}(10 \%)$, RV S' increased by mean (percentage) $1.0 \mathrm{~cm} / \mathrm{s}$ (17\%), RVFAC decreased by mean (percentage) $4 \%$ (14\%), and RVSP decreased by mean (percentage) $19 \mathrm{mmHg}(24 \%)$. The cumulative and individual variation of RV size and function variables is depicted in Figure I and II, respectively. According to the measurements of TAPSE, RV S' and RVFAC, $2 / 7$ (29\%), 2/3 (67\%), and 0/2 (0\%) patients improved their RV function after cannulation, respectively. No patients developed new RV dysfunction after cannulation. After ECMO initiation, TR was mild in 4 patients, moderate in 3 patients, moderate-severe in 2 patients, and severe in 1 patient. LVEF was not significantly different after cannulation. 
ECMO support during echocardiography was median (IQR) 4.7 (3.6-5.4) L/min of blood flow and 4.0 (2.5$5.0) \mathrm{L} / \mathrm{min}$ of sweep gas flow at a $\mathrm{FsO}_{2}$ of $100 \%$. ECMO blood flow and sweep gas flow did not correlate significantly with parameters of RV function and RV size (Table IV). Sweep gas flow had an inverse correlation with RVSP (Pearson correlation coefficient $=-0.68 ; \mathrm{p}=0.03$ ). $\mathrm{PaO}_{2}$ showed a direct correlation with RVFAC (Pearson correlation coefficient $=0.95 ; \mathrm{p}=0.047$ ). From our exploratory analysis, $\mathrm{SaO}_{2}$ before cannulation was significantly lower in non-survivors. No other risk factor for RVD, RV dilatation, or mortality was identified in our population (Supplemental Digital Content II).

\section{DISCUSSION}

In our retrospective study of patients requiring V-V ECMO for severe ARDS, RVD and dilatation before ECMO cannulation were very frequent. ECMO cannulation and the use of an ultraprotective MV strategy were not associated with worse RV function and hemodynamic parameters in these patients.

To our knowledge, our study is one of the first to investigate the impact of an ultraprotective ventilation strategy on RV function during ECMO support. The extensive loss of aeration due to alveolar edema and inflammation and the subsequent low lung compliance, which is characteristic of ARDS, ${ }^{17}$ resulted in extremely low tidal volumes in our patients. These low volumes did not cause a worsening of hemodynamic and echocardiographic parameters or an increase of the RVSP. In fact, RVSP decreased after the initiation of ECMO. This is an important finding considering that up to $64 \%$ of the patients in our cohort had evidence of RVD and $59 \%$ had RV dilatation before cannulation. Moreover, ECMO sweep gas flow was inversely correlated to the RVSP. These findings support the hypothesis that extremely low tidal volumes and atelectasis are not deleterious to the RV if oxygenation and acid-base status are kept within physiologic range through ECMO support. Despite the high number of missing data for RVFAC, the correlation between this index of global RV systolic function and $\mathrm{PaO}_{2}$ may confirm the hypothesis that hypoxemia can have a direct effect on RV function, possibly mediated by the change in pulmonary vascular tone and RV afterload. ${ }^{1}$

The most severe form of RVD, known as ACP, is defined as the association between RV dilatation and septal dyskinesia. ${ }^{6}$ Despite the variability related to the differences in their definitions and study population, severe RVD and ACP occur in about one-quarter of ARDS patients, even in the current era of lung protective ventilation. ${ }^{2}$ One-third to two-thirds of the patients included in our study showed RVD and up to almost $60 \%$ had RV dilatation. Most of the echocardiographic reports did not mention the ratio between RV and LV enddiastolic area or the presence of septal dyskinesia, but qualitative assessments of RV size and measurements of RV longitudinal or global systolic function. Therefore, we could not assess the prevalence of ACP in our population. The association between RV function and mortality has been previously investigated in ARDS patients not supported with V-V ECMO. Although some groups suggested a relation between RV failure and mortality, ${ }^{4-6,18}$ other authors reported dissimilar findings. ${ }^{7,8}$ Differences in study population and definitions of RV failure can explain this controversy. We did not identify any risk factors for RVD or RV dilatation. Importantly, RVD and RV dilatation were not found to be associated with worse clinical outcomes. Our results are not consistent with the findings of Shah et al., who reported that TAPSE was an independent predictor of mortality in ARDS patients. ${ }^{18}$ These patients were not supported with ECMO, which may have been a reason for the discrepancy. Similarly, we did not confirm the independent association of RV dilation with mortality in ARDS patients during V-V ECMO. ${ }^{19,20}$ However, we observed an association between lower $\mathrm{SaO}_{2}$ before cannulation and higher mortality, which may be a sign of more severe disease.

Although not directly affecting cardiac function, V-V ECMO may improve RV function by correcting hypoxemia and allowing the control of deleterious ventilatory settings. ${ }^{1}$ The use of extracorporeal carbon dioxide removal $\left(\mathrm{ECCO}_{2} \mathrm{R}\right)$ decreased pulmonary hypertension and improved RV function in animals, ${ }^{10}$ ARDS patients, ${ }^{13,21}$ and patients suffering from an exacerbation of chronic obstructive pulmonary disease. ${ }^{11}$ Our study confirmed the potential for V-V ECMO to unload the RV in patients with acute respiratory failure. ${ }^{11,13,21}$ However, in patients without alterations of RV function who were weaning from extracorporeal support, V-V ECMO did not alter echocardiographic RV function. ${ }^{22}$ Indeed, in another preclinical model, the use of V-V ECMO was associated with mild myocardium injury, which had no effect on cardiac performance. ${ }^{23}$ Further studies are needed to clarify the effects of extracorporeal circulation on RV function 
and its clinical implications.

It is still unclear whether in patients with ARDS a lung rest strategy, consisting of minimal ventilatory settings to avoid further lung injury related to MV while the lung is healing, is beneficial. This is particularly relevant during ECMO support, when the ventilatory burden can be minimized thanks to the extracorporeal gas exchanges. On the one hand, the effects of severe atelectasis are still debated. In an experimental model, alveolar atelectasis caused vascular leaks and lethal RV failure. ${ }^{24}$ In addition, alveolar hypoxia may lead to lung vascular leak ${ }^{25}$ and induce lung inflammation. ${ }^{26}$ Interestingly, in animals with ARDS supported with V-V ECMO, near-apneic ventilation did not consistently decrease lung injury or early fibroproliferation, when compared to protective and non-protective ventilatory strategy. ${ }^{27}$ On the other hand, further preclinical evidence suggests that ventilation strategies aiming at keeping the lungs partially collapsed and avoiding the opening and closing of collapsed alveoli might reduce the risk of VILI ("permissive atelectasis") ${ }^{28}$ Moreover, VILI with high peak pressure and zero PEEP led to ACP, possibly due to pulmonary microvascular injury. ${ }^{29}$ In the clinical setting, the limitation of lung stress (i.e., Pplat and $\Delta \mathrm{P}$ ), despite not being yet validated in randomized controlled trials (RCTs), has been suggested as part of an RV protective approach. ${ }^{30}$ Additionally, ultraprotective ventilation strategies, which are largely adopted internationally, ${ }^{31}$ have proven to counteract VILI in ARDS patients during $\mathrm{ECCO}_{2} \mathrm{R}^{32,33}$ and V-V ECMO support. ${ }^{34}$ Nonetheless, RCTs are needed to clarify whether the benefits outweigh the risks, as suggested by the SUPERNOVA Trial. ${ }^{35}$

Our findings suggest that a lung rest MV strategy does not lead to further worsening of RV function in ARDS patients during ECMO support. The utilization of moderate levels of PEEP, along with the avoidance of potentially injurious plateau pressure and driving pressure, may have been protective towards the risk of pulmonary vascular dysfunction and RVD. Some clinical studies are ongoing to better investigate this hypothesis (e.g., NCT01990456, NCT03764319). Indeed, the best MV strategy during ECMO support is still not yet defined and wide practice exists worldwide. ${ }^{15,36}$

Although the dosages of vasopressors increased in our population immediately after cannulation, this might have been related to the sedation required for cannulation, rather than being a consequence of the worsening cardiac function. In fact, in a review of the Extracorporeal Life Support Organization Registry, the use of V-V ECMO in patients with ARDS and pre-cannulation hemodynamic support was associated with better survival when compared to veno-arterial ECMO ${ }^{37}$ Additionally, V-V ECMO was shown to reduce the need for vasoactive agents in patients with ARDS and hemodynamic instability on vasopressors or inotropes. ${ }^{14}$

This study has several limitations. First, it was a single-center, retrospective, observational study, with a small sample size. We had to exclude most patients due to missing echoes or echocardiographic parameters. This could have contributed to type II error and limit the accuracy and generalizability of our results. Although by including only patients with echocardiograms performed before and after cannulation we may have reduced the influence of confounding covariates, the high number of missing echocardiographic data requires further studies to confirm our results, which should be considered hypothesis-generating. Second, considering that the echocardiograms were requested for clinical purposes rather than as part of a standardized serial protocol, we cannot exclude selection bias for more severely ill patients and that patients' variable hemodynamic and respiratory conditions affected our findings. Indeed, the Acute Physiology And Chronic Health Evaluation (APACHE) II and Sequential Organ Failure Assessment (SOFA) scores were significantly higher in the study group than the V-V ECMO patients not included in the study (20 [17-24] vs. 17 [13-21], $\mathrm{p}=0.01$, and $11[7-13]$ vs. 8 [5-10], $\mathrm{p}=0.04$, respectively). Third, despite providing data on respiratory mechanics, we did not specifically address the effect of the ultraprotective mechanical ventilation strategy on lung aeration and derecruitment and VILI. Furthermore, the combined measurement of mixed venous oxygen saturation $\left(\mathrm{SvO}_{2}\right)$ and pulmonary arterial pressures could have been valuable to confirm the effect of V-V ECMO on the hypoxic pulmonary vasoconstriction mechanism. ${ }^{13}$ Unfortunately, $\mathrm{SvO}_{2}$ was only measured in a few patients. Fourth, the parameters of RV function measured have not been validated in cohorts of patients supported by V-V ECMO. Limited data have been published on the echocardiographic assessment of RV function during V-V ECMO support. Even though Ortoleva et al demonstrated that qualitative assessment of RV function was feasible in a cohort of 77 patients, they did not use quantitative parameters. ${ }^{38}$ It 
has been demonstrated that during venoarterial ECMO support load-dependent parameters of LV function such as LVEF are not reliable indicators of contractility. ${ }^{39}$ However, venoarterial ECMO bypasses the heart and therefore has a direct impact on RV preload and LV afterload. In a V-V ECMO circuit, the outflow cannula is proximal to the RV and should therefore not affect loading conditions. Moreover, tissue Doppler systolic velocities such as RV S' have been found to be relatively load independent. ${ }^{40}$ In our study, parameters of RV function and size did not correlate significantly with ECMO blood flow and sweep gas flow and only RVSP was inversely correlated with sweep gas flow.

\section{CONCLUSIONS}

In this retrospective study of patients requiring V-V ECMO for severe ARDS, RVD and dilatation assessed with echocardiography were frequent but were not associated with worse clinical outcomes. Our findings suggest that an ultraprotective lung ventilation strategy can be safely implemented in these patients because it was not accompanied by a worsening of RV function. Prospective studies, including serial echocardiographic monitoring of RV function during V-V ECMO support, are needed to assess the effect of lung rest ventilation on RV function. Finally, more data are needed to clarify whether RVD in ARDS patients is a marker of a more severe underlying disease or an independent risk factor for mortality.

\begin{tabular}{|c|c|}
\hline $\begin{array}{l}\text { Table I Baseline characteristics and clinical } \\
\text { outcomes }\end{array}$ & $\begin{array}{l}\text { Table I Baseline characteristics and clinical } \\
\text { outcomes }\end{array}$ \\
\hline Variables & $\begin{array}{l}\text { Median (interquartile range) or number } \\
\text { (percentage) }\end{array}$ \\
\hline Age (years) & $43(33-51)$ \\
\hline Gender (n/\% female) & $8(44.4)$ \\
\hline BMI $\left(\mathrm{kg} / \mathrm{m}^{2}\right)$ & $23(22-26)$ \\
\hline \multicolumn{2}{|l|}{ Comorbidities (n/\%) } \\
\hline CHF & $1(6)$ \\
\hline PAH & $2(11)$ \\
\hline $\mathrm{CF}$ & $3(17)$ \\
\hline ILD & $6(33)$ \\
\hline \multicolumn{2}{|l|}{ Severity score } \\
\hline SAPS II & $32(26-37)$ \\
\hline APACHE II & $20(17-24)$ \\
\hline Hospital LOS before V-V ECMO (days) & $3(0-9)$ \\
\hline MV duration before V-V ECMO (days) & $1(0-3)$ \\
\hline \multicolumn{2}{|l|}{ V-V ECMO configuration (n/\%) } \\
\hline Femoro-jugular & $13(72)$ \\
\hline Bicaval dual lumen & $5(28)$ \\
\hline V-V ECMO duration (days) & $8(6-12)$ \\
\hline \multicolumn{2}{|l|}{ Outcome $(\mathrm{n} / \%)^{a}$} \\
\hline Major bleeding ${ }^{b}$ & $5(28)$ \\
\hline Ischemic stroke & $1(6)$ \\
\hline VAP & $7(39)$ \\
\hline Infection (non-VAP) & $8(44)$ \\
\hline Tracheostomy & $9(50)$ \\
\hline DVT & $3(17)$ \\
\hline $\mathrm{PE}$ & $1(6)$ \\
\hline SVT & $6(33)$ \\
\hline Cardiac arrest & $1(6)$ \\
\hline AKI & $10(56)$ \\
\hline Delirium & $7(39)$ \\
\hline ICU-acquired weakness & $5(28)$ \\
\hline
\end{tabular}


Table I Baseline characteristics and clinical outcomes

28-day vasopressor-free days ${ }^{c}$

IMV duration

ICU length of stay

ICU mortality

Hospital length of stay

Hospital mortality

Death on V-V ECMO

BMI: body mass index; CHF: congestive heart failure; PAH: pulmonary arterial hypertension; CF: cystic fibrosis; ILD: interstitial lung disease; ARDS: acute respiratory distress syndrome; SAPS: simplified acute physiology score; APACHE: acute physiology, age, chronic health evaluation; LOS: length of stay; V-V ECMO: veno-venous extracorporeal membrane oxygenation; VAP: ventilator-associated pneumonia; DVT: deep vein thrombosis; PE: pulmonary embolism; SVT: supraventricular tachycardia; AKI: acute kidney injury; ICU: intensive care unit; IMV: invasive mechanical ventilation. ${ }^{a}$ Patients who died were censored. ${ }^{b}$ Major bleeding was defined as fatal bleeding, or symptomatic bleeding in a critical area or organ (intracranial, intraspinal, intraocular, retroperitoneal, intraarticular, pericardial, intramuscular with compartment syndrome), or bleeding causing a fall in hemoglobin level [?] 20 $\mathrm{g} / \mathrm{L}$, or leading to transfusion of [?] 2 units of packed red cells. ${ }^{c}$ Calculated as the number of days that patients were both alive and free of vasopressor support within 28 days from ICU admission.
Table I Baseline characteristics and clinical outcomes

$20(17-25)$

$18(9-31)$

$26(13-43)$

$4(22)$

$56(35-97)$

$4(22)$

$4(22)$

BMI: body mass index; CHF: congestive heart failure; PAH: pulmonary arterial hypertension; CF: cystic fibrosis; ILD: interstitial lung disease; ARDS: acute respiratory distress syndrome; SAPS: simplified acute physiology score; APACHE: acute physiology, age, chronic health evaluation; LOS: length of stay; V-V ECMO: veno-venous extracorporeal membrane oxygenation; VAP: ventilator-associated pneumonia; DVT: deep vein thrombosis; PE: pulmonary embolism; SVT: supraventricular tachycardia; AKI: acute kidney injury; ICU: intensive care unit; IMV: invasive mechanical ventilation. ${ }^{a}$ Patients who died were censored. ${ }^{b}$ Major bleeding was defined as fatal bleeding, or symptomatic bleeding in a critical area or organ (intracranial, intraspinal, intraocular, retroperitoneal, intraarticular, pericardial, intramuscular with compartment syndrome), or bleeding causing a fall in hemoglobin level [?] 20 $\mathrm{g} / \mathrm{L}$, or leading to transfusion of [?] 2 units of packed red cells. ${ }^{c}$ Calculated as the number of days that patients were both alive and free of vasopressor support within 28 days from ICU admission.

\begin{tabular}{llll}
\hline $\begin{array}{l}\text { Table II Ventilatory, } \\
\text { hemodynamic and } \\
\text { echocardiographic } \\
\text { data before and } \\
\text { after veno-venous } \\
\text { extracorporeal }\end{array}$ & $\begin{array}{l}\text { Table II Ventilatory, } \\
\text { hemodynamic and } \\
\text { echocardiographic } \\
\text { data before and } \\
\text { after veno-venous } \\
\text { oxygenation } \\
\text { cannulation }\end{array}$ & $\begin{array}{l}\text { Table II Ventilatory, } \\
\text { hemodynamic and } \\
\text { echocardiographic } \\
\text { data before and } \\
\text { after veno-venous } \\
\text { extracorporeal } \\
\text { membrane } \\
\text { cannulation }\end{array}$ & $\begin{array}{l}\text { Table II Ventilatory, } \\
\text { hemodynamic and } \\
\text { echocardiographic } \\
\text { data before and } \\
\text { after veno-venous } \\
\text { extracorporeal } \\
\text { membrane } \\
\text { oxygenation } \\
\text { cannulation }\end{array}$ \\
\hline $\begin{array}{l}\text { Variables } \\
\text { Ventilatory variables }\end{array}$ & cannulation & $\begin{array}{l}\text { After V-V ECMO } \\
\text { cannulation }\end{array}$ & value \\
$\begin{array}{l}\text { Minute ventilation } \\
\text { (L/min) }\end{array}$ & $10.8(8.6-11.0)$ & $1.3(0.5-2.5)$ & $<0.01$
\end{tabular}




\begin{tabular}{|c|c|c|c|}
\hline $\begin{array}{l}\text { Table II Ventilatory, } \\
\text { hemodynamic and } \\
\text { echocardiographic } \\
\text { data before and } \\
\text { after veno-venous } \\
\text { extracorporeal } \\
\text { membrane } \\
\text { oxygenation } \\
\text { cannulation }\end{array}$ & $\begin{array}{l}\text { Table II Ventilatory, } \\
\text { hemodynamic and } \\
\text { echocardiographic } \\
\text { data before and } \\
\text { after veno-venous } \\
\text { extracorporeal } \\
\text { membrane } \\
\text { oxygenation } \\
\text { cannulation }\end{array}$ & $\begin{array}{l}\text { Table II Ventilatory, } \\
\text { hemodynamic and } \\
\text { echocardiographic } \\
\text { data before and } \\
\text { after veno-venous } \\
\text { extracorporeal } \\
\text { membrane } \\
\text { oxygenation } \\
\text { cannulation }\end{array}$ & $\begin{array}{l}\text { Table II Ventilatory, } \\
\text { hemodynamic and } \\
\text { echocardiographic } \\
\text { data before and } \\
\text { after veno-venous } \\
\text { extracorporeal } \\
\text { membrane } \\
\text { oxygenation } \\
\text { cannulation }\end{array}$ \\
\hline Tidal volume (mL) & $380(300-410)$ & $150(58-267)$ & $<0.01$ \\
\hline $\begin{array}{l}\text { Tidal volume }(\mathrm{mL} / \mathrm{kg} \\
\text { PBW) }\end{array}$ & $5.2(5.0-6.2)$ & $2.0(0.9-3.6)$ & $<0.01$ \\
\hline $\begin{array}{l}\text { Respiratory rate } \\
\text { (breaths/min) }\end{array}$ & $30(25-32)$ & $10(10-10)$ & $<0.01$ \\
\hline Pplat $\left(\mathrm{cmH}_{2} \mathrm{O}\right)$ & $30(30-34)$ & $20(20-20)$ & $<0.01$ \\
\hline$\Delta \mathrm{P}\left(\mathrm{cmH}_{2} \mathrm{O}\right)$ & $18(18-20)$ & $10(10-10)$ & $<0.01$ \\
\hline $\mathrm{PEEP}\left(\mathrm{cmH}_{2} \mathrm{O}\right)$ & $10(8-15)$ & $10(10-10)$ & 0.45 \\
\hline $\operatorname{Crs}(\mathrm{mL} / \mathrm{cmH} 2 \mathrm{O})^{a}$ & $21(19-23)$ & $9(6-24)$ & 0.08 \\
\hline $\mathrm{FiO}_{2}(\%)$ & $100(80-100)$ & $50(50-50)$ & $<0.01$ \\
\hline $\mathrm{PaO}_{2}(\mathrm{mmHg})$ & $69(62-77)$ & $92(72-135)$ & 0.02 \\
\hline $\mathrm{PaO}_{2} / \mathrm{FiO}_{2}(\mathrm{mmHg})$ & $80(62-87)$ & n.a. & n.a. \\
\hline $\mathrm{SaO} 2(\%)$ & $93(85-95)$ & $96(94-97)$ & 0.02 \\
\hline $\mathrm{PaCO}_{2}(\mathrm{mmHg})$ & $55(49-69)$ & $47(42-50)$ & 0.06 \\
\hline $\mathrm{pH}$ & $7.35(7.19-7.44)$ & $7.35(7.30-7.39)$ & 0.63 \\
\hline \multicolumn{4}{|l|}{$\begin{array}{l}\text { Hemodynamic } \\
\text { variables }\end{array}$} \\
\hline Heart rate (beats/min) & $105(93-124)$ & $95(85-105)$ & 0.18 \\
\hline $\begin{array}{l}\text { Mean arterial pressure } \\
(\mathrm{mmHg})\end{array}$ & $76(68-81)$ & $76(67-81)$ & 0.83 \\
\hline $\begin{array}{l}\text { Norepinephrine dose } \\
(\mu \mathrm{g} / \mathrm{kg} / \mathrm{min})\end{array}$ & $0.00(0.00-0.25)$ & $0.14(0.06-0.31)$ & 0.04 \\
\hline Vasopressin dose $(\mathrm{U} / \mathrm{h})$ & $0(0-0)$ & $0(0-1)$ & 0.03 \\
\hline Lactate (mmol/L) & $1.9(1.6-3.5)$ & $2.2(1.8-4.3)$ & 0.46 \\
\hline Fluid balance $(\mathrm{mL})^{b}$ & $+1462(653-3067)$ & $+838(-37-2268)$ & 0.55 \\
\hline \multicolumn{4}{|l|}{$\begin{array}{l}\text { Echocardiographic } \\
\text { variables }\end{array}$} \\
\hline RV basal diameter $(\mathrm{cm})^{c}$ & $3.9(3.6-4.4)$ & $4.3(3.8-4.5)$ & 0.29 \\
\hline $\mathrm{RV}$ dilatation $(\mathrm{n} / \%)^{c}$ & $6(37)$ & $5(55)$ & 0.16 \\
\hline TAPSE $(\mathrm{mm})^{d}$ & $15(13-20)$ & $15(13-18)$ & 0.41 \\
\hline $\mathrm{RV} \mathrm{S}^{\prime}(\mathrm{cm} / \mathrm{s})^{e}$ & $11.0(9.0-12.0)$ & $12.0(9.5-13.5)$ & 0.61 \\
\hline $\operatorname{RVFAC}(\%)^{f}$ & $29(22-34)$ & $23(20-29)$ & 0.18 \\
\hline $\operatorname{RVD}(\mathrm{n} / \%)^{g}$ & $9(64 \%)$ & $6(50 \%)$ & 0.08 \\
\hline $\operatorname{RVSP}(\mathrm{mmHg})^{h}$ & $58(43-79)$ & $46(34-62)$ & 0.02 \\
\hline $\operatorname{LVEF}(\%)^{i}$ & $60(60-63)$ & $60(48-63)$ & 0.28 \\
\hline
\end{tabular}




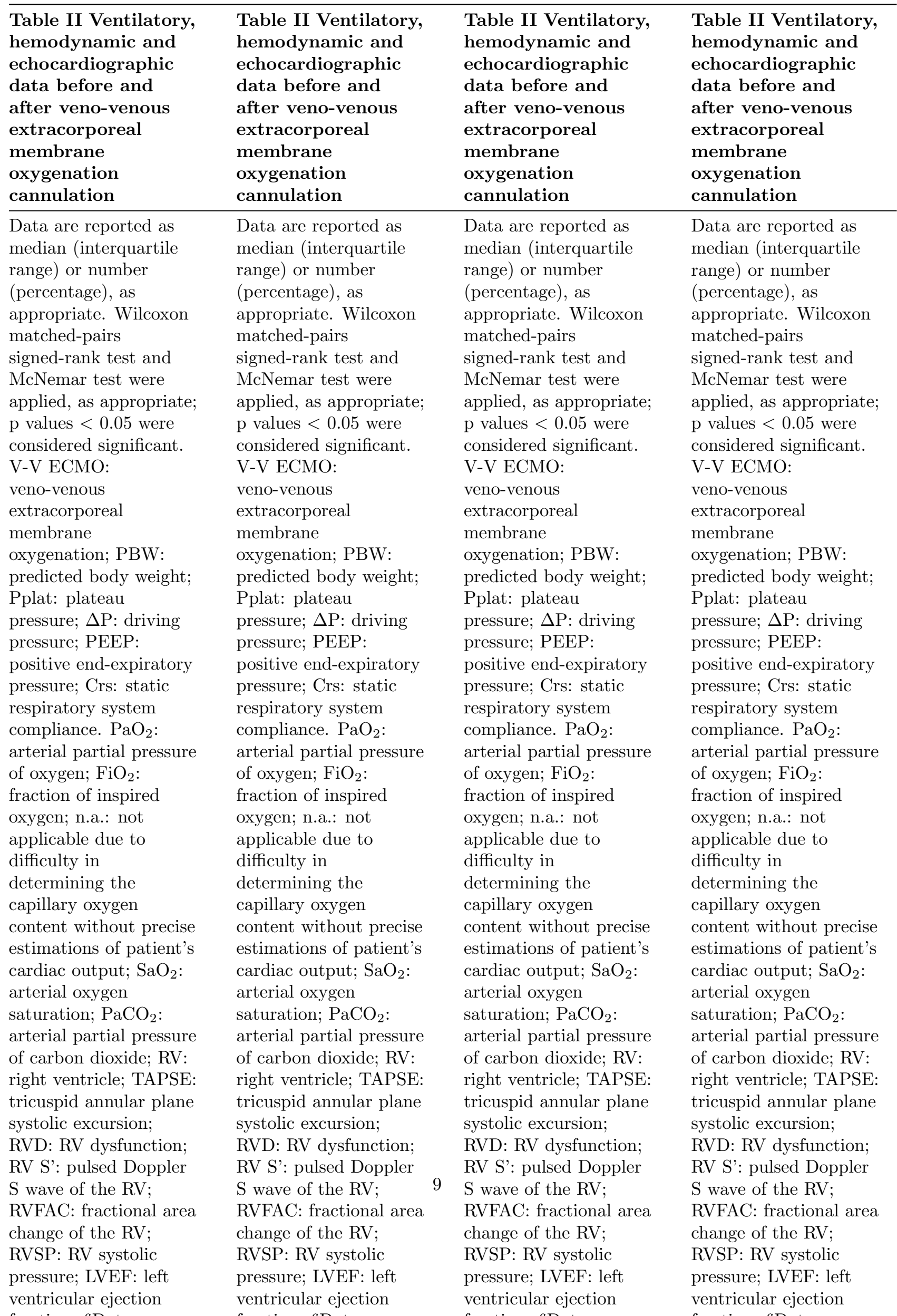




\begin{tabular}{llll}
\hline $\begin{array}{l}\text { Table II Ventilatory, } \\
\text { hemodynamic and } \\
\text { echocardiographic }\end{array}$ & $\begin{array}{l}\text { Table II Ventilatory, } \\
\text { hemodynamic and } \\
\text { echocardiographic }\end{array}$ & $\begin{array}{l}\text { Table II Ventilatory, } \\
\text { hemodynamic and } \\
\text { echocardiographic } \\
\text { data before and }\end{array}$ & $\begin{array}{l}\text { Table II Ventilatory, } \\
\text { hemodynamic and } \\
\text { echocardiographic }\end{array}$ \\
after veno-venous & after veno-venous & after veno-venous & data before and \\
extracorporeal & extracorporeal & extracorporeal & extracorporenous \\
membrane & membrane & membrane & membrane \\
oxygenation & oxygenation & oxygenation & oxygenation \\
cannulation & cannulation & cannulation & cannulation \\
\hline
\end{tabular}

\begin{tabular}{|c|c|c|}
\hline $\begin{array}{l}\text { Table III Right ventricular } \\
\text { size and function before } \\
\text { and after veno-venous } \\
\text { extracorporeal membrane } \\
\text { oxygenation cannulation }\end{array}$ & $\begin{array}{l}\text { Table III Right ventricular } \\
\text { size and function before } \\
\text { and after veno-venous } \\
\text { extracorporeal membrane } \\
\text { oxygenation cannulation }\end{array}$ & $\begin{array}{l}\text { Table III Right ventricular } \\
\text { size and function before } \\
\text { and after veno-venous } \\
\text { extracorporeal membrane } \\
\text { oxygenation cannulation }\end{array}$ \\
\hline $\begin{array}{l}\text { Variables } \\
\text { RV basal diameter }(\mathrm{cm})^{a} \\
\text { TAPSE }(\mathrm{mm})^{b} \\
\text { RV S' }(\mathrm{cm} / \mathrm{s})^{c} \\
\text { RVFAC }(\%)^{d} \\
\text { RVSP }(\mathrm{mmHg})^{e} \\
\text { RV: right ventricle; TAPSE: } \\
\text { tricuspid annular plane systolic } \\
\text { excursion; RV S': pulsed } \\
\text { Doppler S wave of the RV; } \\
\text { RVFAC: fractional area change } \\
\text { of the RV; RVSP: RV systolic } \\
\text { pressure. }{ }^{a} \text { Data available for } \\
8 / 18 \text { patients before and after } \\
\text { cannulation. }{ }^{b} \text { Data available for } \\
10 / 18 \text { patients before and after } \\
\text { cannulation. }{ }^{c} \text { Data available for } \\
7 / 18 \text { patients before and after } \\
\text { cannulation. }{ }^{d} \text { Data available for } \\
2 / 18 \text { patients before and after } \\
\text { cannulation. }{ }^{e} \text { Data available for } \\
9 / 18 \text { patients before and after } \\
\text { cannulation. }\end{array}$ & $\begin{array}{l}\text { Mean difference } \\
+0.1 \\
+1 \\
+1.0 \\
-4 \\
-19 \\
\text { RV: right ventricle; TAPSE: } \\
\text { tricuspid annular plane systolic } \\
\text { excursion; RV S': pulsed } \\
\text { Doppler S wave of the RV; } \\
\text { RVFAC: fractional area change } \\
\text { of the RV; RVSP: RV systolic } \\
\text { pressure. }{ }^{a} \text { Data available for } \\
8 / 18 \text { patients before and after } \\
\text { cannulation. }{ }^{b} \text { Data available for } \\
10 / 18 \text { patients before and after } \\
\text { cannulation. }{ }^{c} \text { Data available for } \\
7 / 18 \text { patients before and after } \\
\text { cannulation. }{ }^{d} \text { Data available for } \\
2 / 18 \text { patients before and after } \\
\text { cannulation. }{ }^{e} \text { Data available for } \\
9 / 18 \text { patients before and after } \\
\text { cannulation. }\end{array}$ & $\begin{array}{l}\text { Mean percentage difference } \\
+3 \\
+10 \\
+17 \\
-14 \\
-24 \% \\
\text { RV: right ventricle; TAPSE: } \\
\text { tricuspid annular plane systolic } \\
\text { excursion; RV S': pulsed } \\
\text { Doppler } S \text { wave of the RV; } \\
\text { RVFAC: fractional area change } \\
\text { of the RV; RVSP: RV systolic } \\
\text { pressure. }{ }^{a} \text { Data available for } \\
8 / 18 \text { patients before and after } \\
\text { cannulation. }{ }^{b} \text { Data available for } \\
10 / 18 \text { patients before and after } \\
\text { cannulation. }{ }^{c} \text { Data available for } \\
7 / 18 \text { patients before and after } \\
\text { cannulation. }{ }^{d} \text { Data available for } \\
2 / 18 \text { patients before and after } \\
\text { cannulation. }{ }^{e} \text { Data available for } \\
9 / 18 \text { patients before and after } \\
\text { cannulation. }\end{array}$ \\
\hline
\end{tabular}

Table IV Correlation between parameters of right ventricula 
Table IV Correlation between parameters of right ventricula 
Positive end-expiratory pressure (PEEP)

Fraction of inspired oxygen $\left(\mathrm{FiO}_{2}\right)$

Driving pressure $(\Delta \mathrm{P})$

Plateau pressure (Pplat)

Tricuspid annular plane systolic excursion (TAPSE)

Pulsed Doppler S' wave (RV S')

RV fractional area change (RVFAC)

Left ventricular ejection fraction (LVEF)

Interquartile range (IQR)

Predicted body weight (PBW)

Arterial partial pressure of oxygen $\left(\mathrm{PaO}_{2}\right)$

Fraction of sweep gas oxygen $\left(\mathrm{FsO}_{2}\right)$

Right ventricular systolic pressure (RVSP)

Tricuspid regurgitation (TR)

Extracorporeal carbon dioxide removal $\left(\mathrm{ECCO}_{2} \mathrm{R}\right)$

Randomized controlled trials (RCTs)

Acute physiology and chronic health evaluation (APACHE)

Sequential organ failure assessment (SOFA)

Mixed venous oxygen saturation $\left(\mathrm{SvO}_{2}\right)$

Authorship: All authors made substantial contributions to the conception and design of the work and the interpretation of data, revised it critically for important intellectual content, and approved the version to be published. TP and MP contributed to the acquisition and analysis of data. TP drafted the work. All authors agree to be accountable for all aspects of the work in ensuring that questions related to the accuracy or integrity of any part of the work are appropriately investigated and resolved.

\section{REFERENCES}

1. Zochios V, Parhar K, Tunnicliffe W, et al. The right ventricle in ARDS. Chest 2017;152:181-193

2. Bunge JJH, Caliskan K, Gommers D, et al. Right ventricular dysfunction during acute respiratory distress syndrome and veno-venous extracorporeal membrane oxygenation. J Thorac Dis 2018;10:S674S682

3. Vincent JL, Zambon M. Why do patients who have acute lung injury/acute respiratory distress syndrome die from multiple organ dysfunction syndrome? Implications for management. Clin Chest Med 2006;27:725-731

4. Bull TM, Clark B, Mcfann K, et al. Pulmonary vascular dysfunction is associated with poor outcomes in patients with acute lung injury. Am J Respir Crit Care Med 2010;182:1123-1128

5. Boissier F, Katsahian S, Razazi K, et al. Prevalence and prognosis of cor pulmonale during protective ventilation for acute respiratory distress syndrome. Intensive Care Med 2013;39:1725-1733

6. Mekontso Dessap A, Boissier F, Charron C, et al. Acute cor pulmonale during protective ventilation for acute respiratory distress syndrome: prevalence, predictors, and clinical impact. Intensive Care Med 2016;42:862-870 
7. Vieillard-Baron A, Schmitt JM, Augarde R, et al. Acute cor pulmonale in acute respiratory distress syndrome submitted to protective ventilation: incidence, clinical implications, and prognosis. Crit Care Med 2001;29:1551-1555

8. Osman D, Monnet X, Castelain V, et al. Incidence and prognostic value of right ventricular failure in acute respiratory distress syndrome. Intensive Care Med 2009;35:69-76

9. Fan E, Gattinoni L, Combes A, et al. Venovenous extracorporeal membrane oxygenation for acute respiratory failure : A clinical review from an international group of experts. Intensive Care Med 2016;42:712-724

10. Morimont P, Guiot J, Desaive T, et al. Veno-venous extracorporeal CO2 removal improves pulmonary hemodynamics in a porcine ARDS model. Acta Anaesthesiol Scand 2015;59:448-456

11. Karagiannidis C, Strassmann S, Philipp A, et al. Veno-venous extracorporeal CO2 removal improves pulmonary hypertension in acute exacerbation of severe COPD. Intensive Care Med 2015;41:1509-1510

12. Cherpanath TG, Landburg PP, Lagrand WK, et al. Effect of extracorporeal CO2 removal on right ventricular and hemodynamic parameters in a patient with acute respiratory distress syndrome. Perfusion 2016;31:525-529

13. Reis Miranda D, Van Thiel R, Brodie D, et al. Right ventricular unloading after initiation of venovenous extracorporeal membrane oxygenation. Am J Respir Crit Care Med 2015;191:346-348

14. Gutsche JT, Mikkelsen ME, Mccarthy FH, et al. Veno-Venous Extracorporeal Life Support in Hemodynamically Unstable Patients With ARDS. Anesth Analg 2017;124:846-848

15. Gattinoni L, Tonetti T, Quintel M. How best to set the ventilator on extracorporeal membrane lung oxygenation. Curr Opin Crit Care 2017;23:66-72

16. Lang RM, Badano LP, Mor-Avi V, et al. Recommendations for cardiac chamber quantification by echocardiography in adults: an update from the American Society of Echocardiography and the European Association of Cardiovascular Imaging. J Am Soc Echocardiogr 2015;28:1-39.e14

17. Ranieri VM, Rubenfeld GD, Thompson BT, et al. Acute respiratory distress syndrome: the Berlin Definition. JAMA 2012;307:2526-2533

18. Shah TG, Wadia SK, Kovach J, et al. Echocardiographic parameters of right ventricular function predict mortality in acute respiratory distress syndrome: a pilot study. Pulm Circ 2016;6:155-160

19. Lazzeri C, Cianchi G, Bonizzoli M, et al. Right ventricle dilation as a prognostic factor in refractory acute respiratory distress syndrome requiring veno-venous extracorporeal membrane oxygenation. Minerva Anestesiol 2016;82:1043-1049

20. Lazzeri C, Bonizzoli M, Cianchi G, et al. Body mass index and echocardiography in refractory ARDS treated with veno-venous extracorporeal membrane oxygenation. J Artif Organs 2017;20:50-56

21. Schmidt M, Tachon G, Devilliers C, et al. Blood oxygenation and decarboxylation determinants during venovenous ECMO for respiratory failure in adults. Intensive Care Med 2013;39:838-846

22. Guinot PG, Soulignac C, Zogheib E, et al. Interactions between veno-venous extracorporeal membrane oxygenation and cardiac function: an echocardiographic study upon weaning. Br J Anaesth 2016;117:821-822

23. Shen J, Yu W, Shi J, et al. Effect of venovenous extracorporeal membrane oxygenation on the heart in a healthy piglet model. J Cardiothorac Surg 2013;8:163

24. Duggan M, Mccaul CL, Mcnamara PJ, et al. Atelectasis causes vascular leak and lethal right ventricular failure in uninjured rat lungs. Am J Respir Crit Care Med 2003;167:1633-1640

25. Carpenter TC, Stenmark KR. Hypoxia decreases lung neprilysin expression and increases pulmonary vascular leak. Am J Physiol Lung Cell Mol Physiol 2001;281:L941-948

26. Madjdpour C, Jewell UR, Kneller S, et al. Decreased alveolar oxygen induces lung inflammation. Am J Physiol Lung Cell Mol Physiol 2003;284:L360-367

27. Araos J, Alegria L, Garcia P, et al. Near-Apneic Ventilation Decreases Lung Injury and Fibroproliferation in an Acute Respiratory Distress Syndrome Model with Extracorporeal Membrane Oxygenation. Am J Respir Crit Care Med 2019;199:603-612

28. Pelosi P, Rocco PRM, Gama De Abreu M. Close down the lungs and keep them resting to minimize ventilator-induced lung injury. Crit Care 2018;22:72 
29. Katira BH, Giesinger RE, Engelberts D, et al. Adverse Heart-Lung Interactions in Ventilator-induced Lung Injury. Am J Respir Crit Care Med 2017;196:1411-1421

30. Vieillard-Baron A, Matthay M, Teboul JL, et al. Experts' opinion on management of hemodynamics in ARDS patients: focus on the effects of mechanical ventilation. Intensive Care Med 2016;42:739-749

31. Schmidt M, Pham T, Arcadipane A, et al. Mechanical Ventilation Management during ECMO for ARDS: An International Multicenter Prospective Cohort. Am J Respir Crit Care Med 2019;200:10021012

32. Bein T, Weber-Carstens S, Goldmann A, et al. Lower tidal volume strategy ([?]3 $\mathrm{ml} / \mathrm{kg}$ ) combined with extracorporeal CO2 removal versus 'conventional' protective ventilation $(6 \mathrm{ml} / \mathrm{kg})$ in severe ARDS: the prospective randomized Xtravent-study. Intensive Care Med 2013;39:847-856

33. Terragni PP, Del Sorbo L, Mascia L, et al. Tidal volume lower than $6 \mathrm{ml} / \mathrm{kg}$ enhances lung protection: role of extracorporeal carbon dioxide removal. Anesthesiology 2009;111:826-835

34. Rozencwajg S, Guihot A, Franchineau G, et al. Ultra-Protective Ventilation Reduces Biotrauma in Patients on Venovenous Extracorporeal Membrane Oxygenation for Severe Acute Respiratory Distress Syndrome. Crit Care Med 2019;47:1505-1512

35. Combes A, Fanelli V, Pham T, et al. Feasibility and safety of extracorporeal CO removal to enhance protective ventilation in acute respiratory distress syndrome: the SUPERNOVA study. Intensive Care Med 2019;45:592-600

36. Kurihara C, Walter JM, Singer BD, et al. Extracorporeal Membrane Oxygenation Can Successfully Support Patients With Severe Acute Respiratory Distress Syndrome in Lieu of Mechanical Ventilation. Crit Care Med 2018;46:e1070-e1073

37. Kon ZN, Bittle GJ, Pasrija C, et al. Venovenous Versus Venoarterial Extracorporeal Membrane Oxygenation for Adult Patients With Acute Respiratory Distress Syndrome Requiring Precannulation Hemodynamic Support: A Review of the ELSO Registry. Ann Thorac Surg 2017;104:645-649

38. Ortoleva JP, Dalia AA, Fiedler AG, et al. Echocardiographic Assessment of Biventricular Function in 249 Patients During the Peri-Extracorporeal Membrane Oxygenation Period. J Cardiothorac Vasc Anesth 2019;33:1325-1330

39. Morimont P, Lambermont B, Guiot J, et al. Ejection Fraction May Not Reflect Contractility: Example in Veno-Arterial Extracorporeal Membrane Oxygenation for Heart Failure. ASAIO J 2018;64:e68-e71

40. Aissaoui N, Guerot E, Combes A, et al. Two-dimensional strain rate and Doppler tissue myocardial velocities: analysis by echocardiography of hemodynamic and functional changes of the failed left ventricle during different degrees of extracorporeal life support. J Am Soc Echocardiogr 2012;25:632640 
figures/Figure-I/Figure-I-eps-converted-to.pdf 
figures/Figure-II/Figure-II-eps-converted-to.pdf 